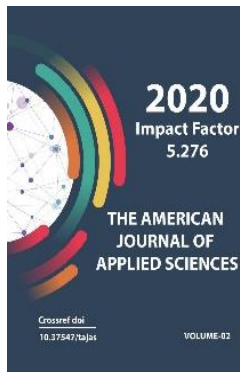

Copyright: Original content from this work may be used under the terms of the creative commons attributes 4.0 licence.

\section{Study Of The Influence Of Radiation Gamma And Thermal Annealing On The Dlts Spectra Of Diodes From Si (Cr)}

Sultanov N.A.

Doctor Of Physical And Mathematical Sciences, Professor, Department Of Physics, Fergana Polytechnic Institute, Fergana, Uzbekistan

\section{Raximov E.T.}

Candidate Of Physical And Mathematical Sciences, Associate Professor, Department Of Physics, Fergana Polytechnic Institute, Fergana, Uzbekistan

Mirzajonov Z.

Candidate Of Physical And Mathematical Sciences, Associate Professor, Department Of Physics, Fergana Polytechnic Institute, Fergana, Uzbekistan

Axmadjonov M.F.

Assistant, Department Of Physics, Fergana Polytechnic Institute, Fergana, Uzbekistan

\title{
ABSTRACT
}

It was shown from capacitive measurements that the concentration of chromium levels decreases after irradiation of the samples with gamma quanta of the $60 \mathrm{Co}$ isotope, and the rate of formation of $\mathrm{A}$ centres in $\mathrm{Si}(\mathrm{Cr})$ is 8-10 times higher than in the control samples.

\section{KEYWORDS}

Irradiation, gamma quanta, 6oCo isotope, $\mathrm{Si}(\mathrm{Cr})$ doped with chromium, radiation defects, rate of formation, charge exchange, complexes, activation of neutral atoms.

\section{INTRODUCTION}

The properties of chromium in silicon have been comparatively poorly studied $[1,2]$. The authors of these works found the following deep levels (DE) associated with chromium. Ec - 0.22, Ec - 0.41, Ec - $0.55 \mathrm{eV}$, their parameters and concentration in $\mathrm{Si}(\mathrm{Cr})$ were determined.
This work aimed to study the effect of gamma irradiation and thermal annealing on DLTS spectra in chromium-doped silicon diodes.

Silicon alloying was carried out by the diffusion method at $1200{ }^{\circ} \mathrm{C}$ for 3-30 hours. 
To measure DLTS, n-Si crystals with an initial resistivity $\rho_{\text {ис }} \cong 5 \div 50 \mathrm{Ohm}$.cm were used.

After diffusion of chromium, they did not change the type of conductivity and their resistance did not change significantly at $300 \mathrm{~K}$, and at $77 \mathrm{~K}$ it increased to

$\rho_{\text {uc }} \cong 10^{3} \mathrm{Ohm} . \mathrm{cm}$.

DLTS measurements were carried out using Schottky barriers. The measurement results did not depend on the nature of the rectifying contact. The DLTS spectra were measured in the constant-capacitance mode in the temperature range $77-300 \mathrm{~K}$ at $\mathrm{t}_{1}=(0,5 \div 50) \mathrm{MC}$, $t_{2}=3 t$. The dimensions of the samples were $12 \times 4 \times 0.8 \mathrm{~mm}^{2}[1,4]$.

\section{MATERIALS AND METHODS}

Irradiation of the samples with ${ }^{60} \mathrm{Co}$ gamma quanta was carried out at a temperature of 30 ${ }^{\circ} \mathrm{C}$ in the dose range $\Phi=2.10^{15} \div 5.10^{18} \mathrm{CM}^{-2}$.

After each stage of irradiation, DLTS spectra were measured in $\mathrm{n}-\mathrm{Si}(\mathrm{Cr})$ control samples. The concentration of $\mathrm{HC}$ in the control samples before irradiation did not exceed $\sim 5.10^{11} \mathrm{CM}^{-3}$ (Fig. 1, curve 1).

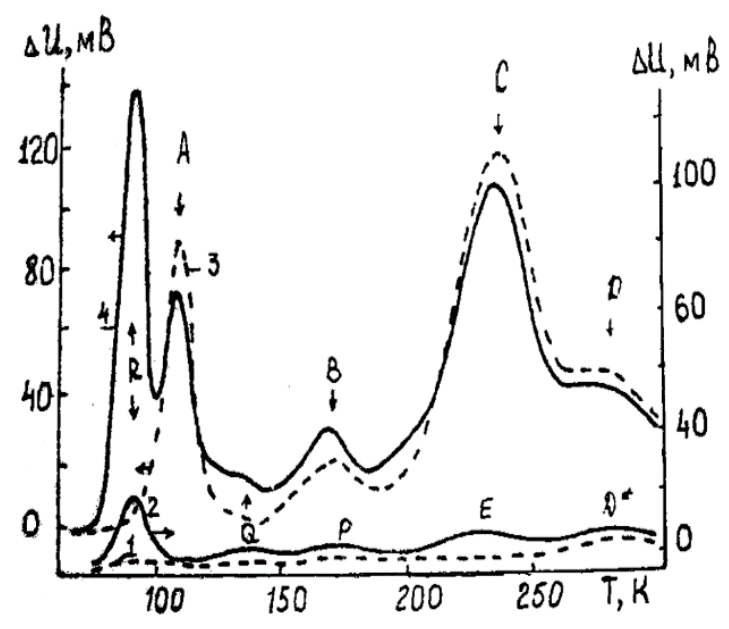

1, 2 - control sample; 3, 4 - $\mathrm{n}$ - Si (Cr); 1, 3 - before irradiation; 2, 4 - after irradiation; $\Phi=5 \cdot 10^{17} \mathrm{CM}^{-2} ; \mathrm{t}_{2}=$ $3 \cdot \mathrm{t}_{1}=6 \mathrm{~ms}$.

Figure: 1. DLTS spectra of Schottky barriers on n-Si.

In all these samples, the concentration of optically active oxygen was $\sim 8.1017 \mathrm{~cm}^{3}$. Measurements showed that in $\mathrm{n}-\mathrm{Si}$, before gamma irradiation, four is associated with chromium are observed (see Fig. 1, curve 3). 


$$
\begin{aligned}
& \mathrm{E}_{1}(\mathrm{~A})=\mathrm{E}_{\mathrm{c}}-0,21 \ni \mathrm{B}, \sigma_{n}(A)=2 \cdot 10^{-14} \mathrm{~cm}^{2}, N_{t}(A)=4 \cdot 10^{13} \mathrm{~cm}^{-3} ; \\
& \mathrm{E}_{2}(\mathrm{~B})=\mathrm{E}_{\mathrm{c}}-0,32 \ni \mathrm{B}, \sigma_{n}(\mathrm{~B})=5 \cdot 10^{-15} \mathrm{~cm}^{2}, N_{t}(\mathrm{~B})=5 \cdot 10^{12} \mathrm{~cm}^{-3} ; \\
& \mathrm{E}_{3}(\mathrm{C})=\mathrm{E}_{\mathrm{c}}-0,43 \ni \mathrm{B}, \sigma_{n}(\mathrm{C})=4 \cdot 10^{-14} \mathrm{~cm}^{2}, N_{t}(\mathrm{C})=4 \cdot 10^{13} \mathrm{~cm}^{-3} ; \\
& \mathrm{E}_{4}(\mathrm{D})=\mathrm{E}_{\mathrm{c}}-0,52 \ni \mathrm{B}, \sigma_{n}(D)=1 \cdot 10^{-14} \mathrm{~cm}^{2}, N_{t}(D)=4 \cdot 10^{12} \mathrm{~cm}^{-3} ;
\end{aligned}
$$

The concentration of $\mathrm{HC}$ in the control samples before irradiation did not exceed $\sim 5.10^{11} \mathrm{~cm}^{-3}$ (Fig. 1, curve 2). After irradiation of control and chromium-doped samples from n-Si, levels $\mathrm{R}$, Q, P, E and $D^{*}$ of radiation defects (RD) are formed (see Fig. 1, curves R, 4) [3]. As can be seen from Fig. 1, after gamma irradiation at a dose of $\Phi=5.10^{17} \mathrm{~cm}^{-2}$, the most noticeable change occurs with the concentration of $A$ centres $\left(E_{a}(R)=E_{c}-0.17 \mathrm{eV}\right)$.

Measurement of the dependence $N_{t}=f(\Phi)$ of radiation defects in $\mathrm{n}$-Si $(\mathrm{Cr})$ showed that changes in the concentration of $\mathrm{N}_{t}$ A centres in all studied samples in the range of irradiation doses $\left(2.10^{15} \div 5.10^{18}\right) \mathrm{cm}^{-2}$ have a linear character, as in $\mathrm{Si}(\mathrm{Zn})[3,5]$.

The rate of change of $\mathrm{N}(\mathrm{R})$ is in $\mathrm{n}-\mathrm{Si}(\mathrm{Cr}) . \vartheta_{R}=$ $\left|\frac{\Delta N}{\Delta \Phi}\right|=5 \cdot 10^{-5} \mathrm{~cm}^{-1}$, whereas in control samples $\vartheta R=5 \cdot 10^{-6} \mathrm{~cm}^{-1}$. This shows that the rate of A-center formation under the same conditions is 8-10 times lower in control samples, that is, $\mathrm{n}-\mathrm{Si}(\mathrm{Cr})$ samples react more strongly to gamma irradiation. It is possible that chromium atoms prevent the direct annihilation of Fresnel pairs, the concentration of vacancies increases and, accordingly, the concentration of defects associated with the samples with vacancies increases.

In chromium-doped samples, in addition to the A centre, a Q level is also formed (Fig. 1, curve 4) which is attributed to divacancies with the parameters $E_{c} \quad-(0,23 \quad \pm 0,1) \quad \ni B$, $\sigma_{n=10^{-15}} \mathrm{~cm}^{-2}$.

The concentrations of the remaining $R D s(P, E$, $\left.D^{*}\right)$ are low, and in chromium-doped samples, these levels are invisible in the DLTS spectra against the background of charge exchange of chromium levels. In the course of irradiation, the chromium concentration decreases monotonically at a comparatively low rate; when the dose changes from 2.1015 to 5.1018 $\mathrm{cm}-2$, the concentrations of levels $E_{1}(A)=E_{c}-0,21$ $\ni B, E_{3}(C)=E_{c}-0,43$ eV and $E_{4}(D)=E_{c}-0,52$ eV fall by about $15-20 \%$ (see Figure 1, curve 4 ).

This shows that, upon irradiation, chromium atoms pass into an electrically inactive state without the formation of stable complexes with primary RDs. The increase in N (B) in $\mathrm{n}-\mathrm{Si}$ $(\mathrm{Cr})$ at high irradiation doses is apparently due to the electrical activation of neutral chromium atoms. It should be emphasized that the decomposition of a defect (complex) during HT depends not only on its properties but also on the properties of other defects present in the crystal and participating in reactions. Chromium HCs in Si are annealed at a relatively low temperature. After HT of the irradiated diodes $\left(\Phi=5.10^{18} \mathrm{~cm}^{-2}\right)$ at $250^{\circ} \mathrm{C}$ for 20 minutes, the chromium level $E_{t}(A)=E_{c}-0,21 \mathrm{eV}$ is almost completely annealed. However, in the process of HT, the formation of stable complexes associated with chromium did not occur. 
Further continuation of the annealing leads to a rapid decrease in $\mathrm{N}(\mathrm{Q})$ and the final decay of the RD. The concentration of chromium levels $C$ and D also noticeably decrease (see Fig. 1, curve 4).

\section{CONCLUSION}

It is shown that the parameters of chromium levels practically do not change as a result of gamma irradiation and chromium atoms do not form complexes with radiation defects in noticeable concentrations. Part of chromium atoms under the influence of gamma irradiation goes into an electrically inactive state. It was found that the presence of chromium increases the rate of RD formation in silicon.

In particular, the rate of A-center formation in $\mathrm{n}$-Si $(\mathrm{Cr})$ diodes is about 8-10 times higher than in the control ones. It is possible that chromium atoms prevent the direct annihilation of Fresnel pairs, the concentration of vacancies increases and, accordingly, the concentration of defects associated with vacancies increases.

\section{REFERENCES}

1. Lebedev A.A., Sultanov N.A. (1970). Some properties of silicon doped with chromium. ФТП. 4(11). p. 2208-2210.

2. Chen, J. W., \& Milnes, A. G. (1980). Energy levels in silicon. AnRMS, 10, 157-228.

3. Lebedev A.A., Sultanov N.A., Ekke V. (1986). Investigation of the effect of gamma irradiation on the spectrum of deep levels in silicon doped with zinc. ФТП. 21(1). p.p. 18-22.

4. Lebedev, A. A., Sultanov, N. A., \& Tuchkevich, V. M. (1971). N-type negative resistance and photoconductivity of sulfurdoped p-type Si(N-type negative resistance, photoconductivity and I-V characteristics of sulfur-doped p-type Si, showing hole capture cross-section dependence on the electric field). Soviet Physics-Semiconductors, 5, 25-31.

5. Lebedev, A. A., Sultanov, N. A., \& Ecke, W. (1987). Influence of uniaxial pressure on transient capacitance spectroscopy of deep levels in SI-ZN. Soviet Physics Semiconductors-USSR, 21(2), 193-195. 